\title{
Laryngeal Squamous Cell Carcinoma
}

National Cancer Institute

\section{Source}

National Cancer Institute. Laryngeal Squamous Cell Carcinoma. NCI Thesaurus. Code C4044.

A squamous cell carcinoma that arises from the larynx. It is the most common histologic type of laryngeal carcinoma. It can arise from the glottis, supraglottic area, or it can be transglottic. Glottic squamous cell carcinoma is the most frequent laryngeal carcinoma in the United States. The symptoms, clinical behavior and the prognosis depend on the site of origin within the larynx. 